\title{
Cambre, Pambre e outros topónimos en -bre
}

\author{
Juan J. Moralejo \\ Universidade de Santiago de Compostela
}

\begin{abstract}
Resumo:
No conxunto de topónimos hispano-célticos compostos con -briga (-bria, -bra, -bre ...) hai algúns anómalos polo fonema nasal $-m$ - que parece cerrar o primeiro termo (por exemplo, Conim-briga, Cam-bre ...). Proponse aquí unha reinterpetación etimolóxica que corrixe esa anomalía: en Coni-mbriga, Ca-mbre ... non temos -briga 'altura > castro, vila', senón -mbriga 'marca, linde, territorio'.
\end{abstract}

Palabras chave:

Linguas paleohispanas, toponimia céltica en -briga, -mbriga.

\begin{abstract}
:
Among the hispano-celtic toponyms with second term -briga (-bria, -bra, -bre ...) there are some anomalous items whose first term seems to end in a nasal phoneme-m-(Conim-briga, Cam-bre ...). We propose a new etymology in order to eliminate this formal anomaly: in Coni-mbriga, Ca-mbre ... we do not have -briga 'height > town', but -mbriga 'border, land'.
\end{abstract}

Key words:

Palaeohispanic languages, celtic toponymy in -briga, -mbriga.

No mapa de Hispania hai unha notable cantidade de topónimos formados co lexema brüg-, que pode ser raíz de termos simples (Brigaecium, Brigantium, Brigantia) e, sobre todo, pode ser segundo elemento de termos compostos (Mirobriga,

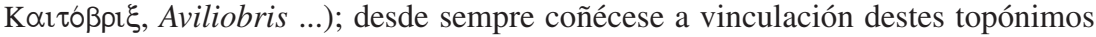
cos celtas, celtíberos e célticos de que falan as fontes literarias e sábese que -briga significa 'vila, cidade'; os nomes híbridos Augustobriga, Flaviobriga, Caesarobriga, etc. (cos seus paralelos doutras áreas célticas, Augustodunum,

1 Estas notas de toponimia son do Proxecto de Investigación Hidronimia Prerromana de Gallaecia, subvencionado pola Xunta de Galicia (PGIDT99PXI20402A), en que traballo coa colaboración inestimable da Prof ${ }^{\mathrm{a}}$ Titular Dr ${ }^{\mathrm{a}} \mathrm{M}^{\mathrm{a}}$ Xosé García Blanco.

Nas citas bibliográficas atéñome ás siglas habituais en L'Année Philologique e máis na Linguistic bibliography... / Bibliographie linguistique ... (Dordrecht: Spectrum, 1948-). 
Caesarodunum, etc. ) que romanos e indíxenas romanizados deron a vellas ou novas entidades de poboación certifican o que digo. Desde moito antes de que a Lingüística teña rigor en Historia e Comparación de linguas, tamén se sabe que o reparto de -briga se contrapón ó dos topónimos ibéricos, non indoeuropeos (S. e E. de Hispania), Ilerda, Iluro, Iliturgi ... en que se recoñece un primeiro termo ili-, ilu(e outras variantes ilti-, iltu- ...) que tamén parece significar "vila, cidade'2

En Humboldt, Prüfung der Untersuchungen über die Urbewohner Hispaniens vermit-

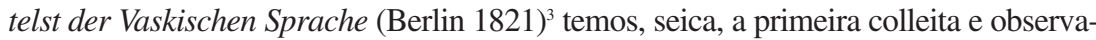
ción sistemática dos topónimos en -briga, pegada dunha poboación céltica dentro da unidade e do protagonismo (vasco-)ibérico que Humboldt afirmaba para Hispania. Os topónimos con segundo termo -briga, -brix ocuparon lugar importante na obra doutros estudiosos do celtismo hispano, por exemplo, D'Arbois (1893-1894) e, sobre todo, Untermann (1961), que con eles e outros materiais onomásticos delimitou a Hispania indoeuropeizada, en contraposición, mais tamén superposición, coa non indoeuropea dos topónimos ibéricos con $i l(t) i$-, il(t)u- (Iltirta / Ilerda, etc.) e dos topónimos meridionais e sudoccidentais con sufixos (ou lexemas) -ippo, -uba, -igi, -ucci y -urgi (Olisippo, Onuba, Astigi, Itucci, Aurgi ...). No acopio e na interpretación de topónimos con -briga e demais variantes antigas, medievais e modernas destacan os estudos de Albertos (1990), Búa (2000), Búa / Lois (1995), Caro Baroja (1946, 1947, 1954), Menéndez Pidal (1952), Moralejo (1953), Untermann (2001) e Villar (1995a).

$\mathrm{Na}$ interpretación de -briga e das súas variantes tamén antigas -brix, -bris Humboldt non puido pasar de observar homofonías (non probatorias) con outros elementos indoeuropeos de significación igual ou semellante; hoxe é maioritaria a remisión a IEW 140 *BHEREGH- 'hoch, erhaben', *BHERGHOS 'Berg', LIV *BHERGH'hoch werden, sich erheben', raíz ${ }^{4}$ que desde o seu grado cero ou ausencia de vocal, *BHRGH- evoluciona a BRIGG-, con deaspiración dos fonemas oclusivos, ${ }^{*} b h$ - $>b$-, $*_{-} g h->-g-$, e con vocalización $*_{-}-r_{-}>-r i-$, dous feitos que encaixan plenamente no

2 Nótese o contraste tipolóxico, orde determinante + determinado no indoeuropeo céltico Miro-briga, Nemeto-briga, fronte a determinado + determinante no ibérico, non indoeuropeo, Ili-berris, Ili-turgi (e no vasco Etxe-berri, Lumbier < *Ilun-berri). Véxase tamén que esa orde non indoeuropeo en "orixe" é a que hoxe temos nos románicos Vilanova, Villanueva, Villeneuve ... (¡orde OTAN!) fronte ó mantemento da orde indoeuropea nos xermánicos Newcastle, Neuburg, no eslavo Novgorod e no grego

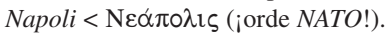

3 Hai traduccións de F. Echebarría, Primitivos pobladores de España y lengua vasca (Madrid: Ed. Minotauro, 1959), e de R. Ortega, Los primitivos habitantes de España: investigaciones con el auxilio de la lengua vasca (Madrid: Ariban y Cía, 1879; reed., Madrid: Polifemo, 1990)

4 Téñase en conta que a cita das raíces non esgota as súas variantes fono- e morfolóxicas, polo que a forma principal nos diccionarios pode non ser a antecedente directa da documentación que analizamos. O LIV ten fronte ó clásico IEW a vantaxe de incorporar a chamada 'teoría laringal' (notacións $* h_{l} * h_{2}$ $* h_{3}$ para fonemas "larinagais" de documentación moi parcial, pero de gran rendemento en comparación e reconstrucción). 
que define o Céltico Común verbo das súas orixes e mais dos seus adláteres indoeuropeos. A significación orixinaria de 'altura, elevación' no terreo deriva fácilmente á de 'vila, cidade' e, se fan falla probas, abonda con recordar qué é un castro, a altura ben defendida, apta para habitación segura, e que quizais da mesma raíz, grao pleno *bhergh-, temos o Bergidum > O Bierzo, 'A Montaña'. Son dos que pensan que os nominativos de singular xa antigos -briga, -bria, -brica, -brix, -bris e as súas evolucións medievais e actuais -bria, -bra, -bre, -be, -ve (e outras solucións particulares, por exemplo, as que temos en Setúbal, Sepúlveda ...) pódense reducir a esa orixe única da que, por certo, ademais do céltico -briga (-brix, -bris), temos a toponimia xermánica con segundo termo -burg, -borough (Magdeburg, Marlborough ...). Recordemos tamén que o hispánico -briga contrasta co galo e británico -dunum, tamén 'vila, castro' (Lugudunum, Camulodunum ...), anque o tipo -briga tamén é extrahispánico, mentres -dunum é moi raro ou dubidoso en Hispania.

Mais cómpre termos presente que para as formas antigas en -bris (Aviliobris, $\Lambda$ ovdoßpís ...) e as súas continuacións medievais e modernas en -bre, -be, -ve (Deixebre, Cortobe, O Grove), temos, por exemplo en Monteagudo (1986) e en Búa / Lois (1995), outra alternativa etimolóxica, con remisión a IEW 1151.2 *WER-, erweitert *WER-D-, *WER-S- 'erhöhte Stelle (im Gelände oder in der Haut)', ... cf. lat. uarix e uerruca como prominencias ou protuberancias na pel; en Búa / Lois (1995: 40) proponse un grao cero radical e sufixación $*-i h_{2}$, é dicir, *WR-Ī-, que con betacismo acaba sendo o nom. sg. -bris (cf. Aviliobris, Bañobre, Castrove ...) $)^{5}$. Distinta liña etimolóxica, pero a fin de contas a mesma liña semántica da elevación do terreo elixida como asentamento, fortificado ou non, de poboación; mais ningunha de esas dúas alternativas é ou parece aplicable ó monllo de topónimos que imos revisar.

No conxunto de topónimos en -briga, -brix, -bris, -bria, -bre etc. son minoría reducida os topónimos con fonema nasal $-m$ - ante -briga e as súas variantes, mentres son maioría absoluta xa en data antiga os segmentables de forma clara con un primeiro elemento de final vocálico ${ }^{6}$. Que o primeiro termo do composto teña final

\footnotetext{
Á posición de Búa / Lois adheriuse Untermann (2001: 193). Pero Búa (2000: 151) abandona a súa posi-

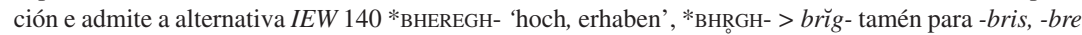
... A posición de Búa / Lois (1995: 35) debe ser corrixida no seu dictame de que os actuais topónimos en -bre non teñen documentación medieval en -bria e, polo tanto, se exclúen da orixe -brig-. Nótese que o actual galego Cambre, portugués Cambra, asturiano Calambre en documentación medieval é Calambria, Caambria, Caambraha, Caumbria, Kalumbria, Calamber, Calambre; o actual Pambre foi medieval Paambra, que supón a variante *-BRIA <-*BRIGA; pero, na alternativa etimolóxica que agora presentamos, estes topónimos con - $m$ - ante -briga, -bria, -bris, -bre non son totalmente decisorios porque a nosa opción para eles non é nin *-BRIG- nin *-WRĪ-.

6 Dun final vocálico ante -briga apártase Perbrigam, unha mansio que coñecemos soamente pola Ravennatis Anonymi Cosmographia; non podo negar ou emendar esa forma (¿síncope recente de - $V$-?), pero si recordar con qué frecuencia dá esa Cosmographia formas pouco fiables. Roldán (1975: 257) supón que Perbrigam podería identificarse con Ierabriga.
} 
vocálico encaixa plenamente nas regras da composición nominal indoeuropea: a vocal mais frecuente é a chamada vocal temática, de timbre alternante e/o, e non faltan os timbres $a, i, u$ propios dos correspondentes temas morfolóxicos ou doutras orixes. O que se observa en Nemeto-, Miro-Arco-Caeto-Avilio, Londo-, etc. ante -briga, -brix, -bris ... ten abondoso paralelo nos compostos en que o segundo termo é -dunum, -magos e outros tipos característicos do ámbito céltico (Eburodunum, Eburomagus, Eburobriga, Eburobrittium ... $)^{7}$. Nun resumo suficiente e que pode prescindir da minucia filolóxica ${ }^{8}$ temos en -briga e o seu grupo:

1) -V-briga, con timbre -o-, Arcobriga, Nemetobriga, Mirobriga ...; con timbre - $a$-, Arabriga; Ierabriga, Talabriga ...; ademais, os híbridos Augustobriga, Flaviobriga ...; 2) -V-brica, con timbre -o-, Abobrica; con timbre -a-, Ierabrica; híbridos Augustobrica, Augustabrica. En -brica o gutural xordo - $c$ - é mera grafía hipercorrecta fronte á tendencia a eliminar os fonemas oclusivos sonoros intervocálicos

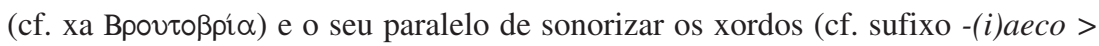
-(i)aego). As variantes 1) e 2), coas súas evolucións xa antigas, medievais e modernas censadas en 3), 4) e 5), poden ser adaptacións ou retematizacións latinas do orixinario *BHRGH-S > -brix a partir do ac. sg. *-BHRGH-M. $>$ - brigam.

3) -V-briga, -V-brega medievais ou actuais, Alpuébrega ...; 4) -V-bria, antigos e

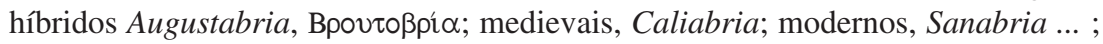
5) -V-bra, medieval Anobra, actual Seabra ...

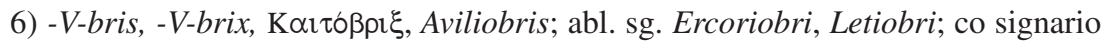
ibérico temos celtib. nertobis [= nertobri $x$ s], celtib. segobris [segobris] abl. sg. celtib. sekobiriked [= segobriged]; 7) -V-bre, Alcabre, Deixebre, Pantiñobre ... ; 8) -V-ve o -V-be, O Grove, Cortobe, Trobe ... Nótese en 6) que a variante -bris, antecedente do medieval e moderno -bre, é xa antiga, xurdida por reducción de -brix $(-k s)$ a -bris no nominativo de singular e remodelación de toda a flexión como tema en $-i$-. As variantes actuais -ve, -be proceden de metátese (*MonToBRE > Montrove), ou de disimilación (*CASTROBRE > Castrove, medieval Talobre > Trobe), ou de ambas (*OCROBRIS $>$ medieval Ocobre, Ogovre $>$ O Grove).

Na documentación medieval e moderna segue a ser predominante o timbre - o- e as súas evolucións no final do primeiro termo do composto (Baño-bre, con ditongación o toledano Alpué-brega ... ), pero tamén hai -a-(Alca-bre, Sana-bria ...) e non

7 Prá regularidade do final vocálico nos primeiros termos de composto e as consecuencias na súa análise véxase que Untermann (1999: 185) ten por "absolutamente inverosímil" que o topónimo catalán Besalú, se procede de un *BESALDUNUM, poida ser celta "dado que el primer componente Besal- no encuentra ningún apoyo en el léxico de las lenguas celtas, y dado que todos los topónimos celtas con -dunum presentan una vocal delante de la d" (A itálica é miña).

8 Remítome a Roldán (1975), a Tovar IL e mais á TIR. 
faltan outros timbres (Deixe-bre, Alxi-bre, Alú-briga, Lu-bre ...) que poden ser antigos ou tamén xa secundarios, debidos a asimilacións, disimilacións, adaptación do timbre vocálico ó punto de articulación dos fonemas consonánticos inmediatos, etc.

O timbre - $a$-, non escaso en exemplos xa antigos (Arabriga, Talabriga, Sanabria, Ierabriga ...), podería prestarse a discusións sobre xénese e evolución do vocalismo indoeuropeo (en concreto, "orixes" e mapas dos timbres * $a$ e *o) e máis sobre estratificacións indoeuropeas en Hispania (por exemplo, consideración dos datos da hidronimia paleoeuropa, alteuropäische Hydronymie de Krahe (1954, 1962, 1964), e a veterana discusión sobre a celticidade de certos materiais lusitanos e galaicos fronte á celticidade obvia do celtibérico, coa consecuencia axiomática de que teñamos Onomástica híbrida.

En efecto, calquera que sexa o timbre vocálico que precede a -briga e variantes, hai que reparar en que os antigos Augustobriga, Caesarobriga ... e os actuais Castrove, Sillobre ... son híbridos que nos recordan a necesidade axiomática de que tamén nas formas integramente prerromanas se rexistren hibridacións que nos remonten mesmo ó preindoeuropeo, mais ou menos pasado pola peneira fónica e formal para o adaptar a bocas e pautas indoeuropeas ${ }^{9}$, e tal vez nos remonten tamén a estratos ou variantes dentro da indoeuropeización de Hispania. Polo tanto, ademais de dificultades e perplexidades étimo-semánticas, tamén posibles irregularidades ou imprevistos en Fono- e Morfoloxía ${ }^{10}$.

Fronte a esa maioría antiga, medieval e moderna, de final vocálico para o primeiro termo do composto, hai unhas poucas excepcións, reais ou aparentes, tamén antigas, medievais e modernas, que presentan o seu primeiro termo con final consonántico, nasal -m-. Empezarei por eliminar algunhas formas para as que considero outra liña etimolóxica ou que xustifican ben ese $-m$ - final do seu primeiro termo:

1) o río Lambre (Ría de Betanzos C), medieval Lambre, Lamber ... recórdanos a $\Phi \lambda \alpha$ oví $\alpha \Lambda \mu \beta$ ßí $\varsigma$ de Ptolomeo 2.6.26, capital dos (xen. pl.) B $\alpha \mathbf{\delta} v \omega v$, galaicos lucenses, poboación de difícil identificación coa Lambriacam urbem de Mela 3.10

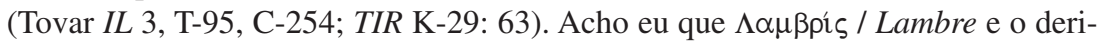
vado Lambriacam pódense adscribir a IEW 660 * $\mathrm{LEG}^{\mathrm{W}} \mathrm{H}-$ ' leicht in Bewegung und

9 As palabras de Mela 3.15, Cantabrorum aliquot populi amnesque sunt sed quorum nomina nostro ore concipi nequeant (e textos similares de Estrabón e Plinio) non se aplicarán soamente ó que un heleno ou romano senten ante nomes bárbaros escuros e malsoantes. É axiomático que en todo contacto de linguas hai dificultade ou estrañeza dos falantes de unha ante formas da outra, coas inevitables alteracións e adaptacións nas formas que eses falantes incorporan ós seus usos.

${ }^{10}$ E sen esquecermos que algúns nomes en -bre, -bra, etc. poden ter etimoloxías que, pese ás aparencias, os exclúen do conxunto que agora tratamos. Véxase mais abaixo o que se di dos Cambra portugueses. 


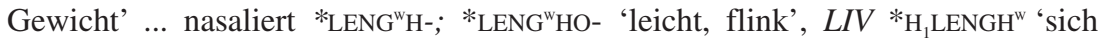
mühelos bewegen', é dicir, á base * $\mathrm{H}_{1} \mathrm{LNGH}^{\mathrm{W}}$-RI-, 'lixeiro, rápido’ (cf. 'દ $\lambda \alpha \phi \rho o ́ \zeta$ 'lixeiro' e o hidrónimo Lambrus, en Italia e ilírico segundo Krahe (1954: 121), coa observación de que, mentres $*_{-} g h^{w}->-b$ - non ten bo encaixe no céltico, si o ten a evolución $*_{n}>a m$. Non argumento, simplemente constato, que a un río como o Lambre acaelle ben chamarse "rápido, lixeiro'" .

2) o río Tambre (Ría de Noia C) (medieval Tamaris, Tamar, Tamare, Tamar) é o

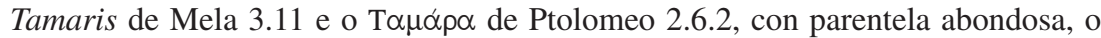
antigo Tamesis ou Tamesa, hoxe Thames, en cabeza. Por tanto, nada que ver con -briga e as súas variantes.

3) Ombre (Pontedeume, Brión, Culleredo C): o Ombre de Pontedeume na documentación medieval do mosteiro inmediato de Caaveiro é repetidamente Anobre, Anovre, Ovre, Oovre, polo que non hai dúbida de que estamos ante un topónimo con segundo elemento -bris > -bre e o elemento nasal que o precede é o intervocálico do primeiro termo ano-, nasal que se vai perder, pero nasalizando o vocal seguinte, en proceso absolutamente regular e frecuente na lingua galega, sen que importe que as grafías medievais Ovre, Oovre non fagan explícita esa nasalidade que si se fai hoxe en Ombre. Polo tanto, a segmentación Om-bre está xustificada e non é excepción á regra de que a -briga, -brix, -bris ten que os preceder fonema vocálico $^{12}$.

4) O rioxano Hambre e outros Hambre (con $h$ - reetimoloxizante), Ambra de Huesca, Cáceres, Guadalajara, etc. que recolle Prósper (2002: 105) $)^{13}$ e que son do ámbito hidronímico, poida que sexa mellor integralos no conxunto hidronímico céltico documentado en varios Ammer, Amper, Amber, Ambre, etc. que Krahe (1964: 90) remite a Ambra (tamén Ambris, cf. Tamara / Tamaris). O conxunto pódese remitir a IEW 315.2 * (ENEBH-), *NEBH-, *EMBH-, * ${ }^{*} \mathrm{MBH}-$ 'feucht, Wasser' ... coa base * ${ }_{\mathrm{MBH}} \mathrm{R}(\mathrm{O})$ - sufixada en $* \mathrm{MBH}-\mathrm{R}-\mathrm{EH}_{2}-\mathrm{ou} * \mathrm{M}_{\mathrm{o}} \mathrm{BH}-\mathrm{R}-\mathrm{IH}_{2}-$ Polo tanto, nada que ver con -briga, -brix, -bris.

11 De Lambre e outras formas con etimoloxías que comportan fonemas labiovelares trato en "Labiovelares en material galaico y lusitano" (no prelo, para Verba. Anuario Galego de Filoloxía).

12 Cf. Ferreiro (1995: 125-130), Piel (1962), Moralejo (1977a).

O topónimo pontedeumés Ombre ten unha longa historia de desacertos académicos e non académicos: a homofonía con hombre e o andacio da castelanización a eito da toponimia galega teñen producido hipóteses académicas de que $(H)$ ombre estea por un auténtico *Home que serve para argallar conexións con Eume. E a preguiza para lle dar un repaso ó tumbo de Caaveiro e recoñecer Anobre > Ombre tamén derivou a etimoloxías fantasiosas pró presunto par Ombre / Eume. As brochas hinsidiosas (véxase Catulo 84) dos celotes ortografistas do $h$ seguen sen deixar en paz a Ombre na sinalización de estradas.

13 Véxase tamén Villar (1995a: 158, n. 33) para outras formas non galaicas en -bre e problemáticas no seu encaixe no grupo en que estamos a falar. 
Pasamos agora a revisar os poucos topónimos nos que a análise habitual nos dá un primeiro termo con final consonántico - $m$ - que non parece compatible coas regras vixentes na composición nominal indoeuropea e céltica.

O punto de partida témolo na vella Conimbriga, que é hoxe Condeixa-a-Velha, pois a actual Coimbra é a súa refundación, despois da destrucción polos suevos, na que foi Aeminium. Na documentación temos Conimbriga, Conimbrica, Conembriga, Conimbria, Colimbria ... cos derivados xen. sg. Kovı $\mu \beta p \imath \eta \sigma_{i} \alpha$, Conimbriensis, Coimbriensis, Coimbrensis ... e na documentación medieval Conimbrianos, Colimbrianos etc. $-i$ de repoboacións medievais ou mais ben xa antigos, debidos a refuxiados trala destrucción polos suevos?- antecedentes dos actuais e repetidos Cumbráns, Cumbraos ${ }^{14}$. Fronte á maioría clara de Conimbriga e afíns temos Coniumbrica / Coniumbriga en Plinio 4.113 e unha lectura discutible CONIVM[brig(ensis)] en CIL 2, 5866; ademais, CONIVMBRIG(ensium?) en CIL 2, 432 puidera referirse a unha segunda $*$ Coniumbriga ${ }^{15}$.

A clara maioría de Conimbriga en data antiga fronte a Coniumbriga e mais o feito de que Conimbriga sexa a única forma antiga de que arrincan as formas medievais e modernas nos suxiren que nos raros Coniumbriga e Coniumbrig(ensis) a grafía -iu- poida representar unha realización labial do /i/ ante o nasal labial $/ \mathrm{m} /$, é dicir, unha realización /ï/ que acaba desprazada pola normal /i/16.

Verbo do que realmente importa, o nasal -m- (ante -briga, -bra, -bre ...), direi que non me parece convincente Blondin (1977: 149) en que poida ser epentético "devant la labiale $b$ fortement articulée, en sorte que - $b$ - et - $m b$ - y sont en variation libre". Tampouco non creo que Conimbriga poida proceder dun *CONENO-BRIGA ou similar, con síncope de que resulta a secuencia -mbr- (Holder: 1102). Imponse a segmentación Coni-mbriga, que non será un caso illado, como axiña veremos ${ }^{17}$.

14 Véxase Piel (1951). En Ponferrada LE hai un Columbriano que tal vez supoña unha *CoLuMBRIGA ou sexa remisible á nosa Conimbriga, pero tamén puidera ter orixes que non afectan ó noso tema.

15 Para toda esta documentación e os seus problemas cf. Encarnação (1975), Garcia (1991), Guerra (1999).

${ }^{16}$ O galaico Calubrigen(sis) pode ser exemplo da acción do labial - $b$ - sobre o timbre $(i * a$, *o?) do fonema vocal precedente. Véxanse as variantes medievais Kalumbria, Caumbria da Calambria, Caambria, actual Cambra, que logo revisaremos.

17 A segmentación anómala Conim-briga foi observada pola práctica totalidade dos que se ocuparon dos topónimos con -briga, pero son poucos os que se detiveron nela, por exemplo, Piel (1977: 162) e Blondin (1977: 148).

Evidentemente, hei de contar coa posibilidade de que en última instancia o escuro para nós, preindoeuropeo ou non, sexa simplemente *CONIM- e que non haxa máis que aceptalo e non discutir a análise tradicional de Conimbriga como composto con -briga. Esta mesma posibilidade podería estar nos outros topónimos con secuencia -mbr- que aquí revisamos. 
Téñase en conta que xa desde Leite de Vasconcellos o estudo de Conimbriga /

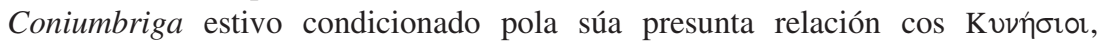

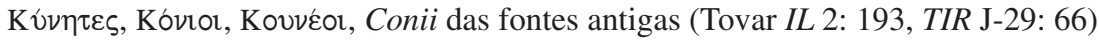
e a súa posible expansión desde Algarve e Alentejo ata máis arriba do Tejo, mais non houbo, seica, tal expansión e as hipóteses etimolóxicas baseadas nela perden moito da súa forza, ou toda ${ }^{18}$. Entre as hipóteses que relacionaron Conimbriga cos Conios cómpre destacar a de ver en Coniumbriga (Schmoll 1959: 32, Tovar IL 2: 194 e 260) un 'agregado' ou falso composto dos sustantivos Conium (xenitivo plural) e *briga ${ }^{19}$, unha 'dos conios cidade', en paralelo a Conistorgis / Conisturgium do Algarve, nome de conexión mais clara, seica, cos Conii.

Hai outras propostas nas que a presunta relación de Conimbriga cos Conii e mais con Conistorgis quere dar a estos termos unha etimoloxía indoeuropea e, no marco de esquemas migracionistas ou invasionistas da indoeuropeización de Hispania, detectar estratos pre- ou para-célticos de xentes ilirias, ambroilirias, ligures, etc. das que os Conii serían parte; pero todo eso hai tempo que devalou e o que teña de realidade encaixa noutros modelos que non é momento de pre$\operatorname{sentar}^{20}$.

O que agora importa é que todo canto se fale nunha etimoloxía indoeuropea para Conistorgis, Conisturgium no seu segundo elemento ou en ambos, non pode esque-

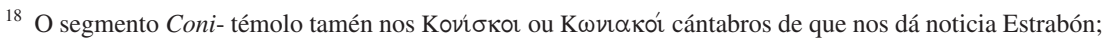
ademais, o antropónimo Conicodius, que, anque documentado no Alentejo, non é de relación segura cos Conii e a súa cidade Koví $\sigma \tau \rho p \gamma \imath \varsigma$; outras referencias poderían ser o antropónimo Conisovinus en Holder (I, 1102) e o antropónimo Coni-letus en Schmidt (1957: 183).

19 No celta hispano soamente temos -briga en composición ou derivados de brig(a)-, pero puido haber o substantivo simple *BRIGA (cf. irl. brí, galés e bret. bre 'outeiro').

Se aceptamos o falso composto Coniumbriga, perde forza a obxección de Blondin (1977: 150) á rareza de que nun composto -briga teña como determinante un etnónimo. O composto regular sería * KON(Y)O-BRIGA.

${ }^{20}$ En Schmoll (1959: 32), "Zusammenrückung" *CONI(O)S *TorgIS > Conistorgis, con -torgis, "mercado, foro', de ide. *TRG-, cf ilirio Tergeste, actual Trieste, eslavo *TERG- 'mercado'. Coa segmentación Conis-torgis, Tovar (1957), seguindo a Krahe (1955: 105), propón un *-DORGIS, de IEW 254 * DHEREGH'festhalten, fest', na liña semántica de 'vila, castro (dos conios)' como lugar naturalmente forte ou fortificado. Nesa mesma liña tamén poderíamos optar por un *-STORGIS, de IEW $1022.1 *(\mathrm{~s})$ TER-, *(S)TER $\partial-$, *(S)TRE- 'starr, steif sein, starrer, fester Gegenstand ...' [mellor, *(s)TER-, *(s)TER-H-, *(s)TR-EH - - ], con alongamento gutural, *(S)TER-G-, *(s)TR-EG-; nótese que teriamos unha segmentación Coni-storgis que nos permitiría enlazar con Coni-mbriga.

Hai outras etimoloxías: para os Conii Blondin (1977: 152 e 156) pensa en ide. *KWON- 'can', ou nunha base oronímica $\mathrm{K}^{\mathrm{O}} \mathrm{N}$ 'éminence pierreuse'; para Coni- Búa (2000: 95) pensa en ide. *KOMYO- > *KonYO'común', pero, digo eu, esperaríamos *CONIO-BRIGA ou, dentro da súa proposta, *CoNIO-MBRIGA, en paralelo a cómo se presentan as formas con sufixo *-yo-, cf. Medio-lanum, Novio-dunum, Blanio-brensis, etc. 
cer que, con Isturgi, Iliturgi, etc. forman un conxunto non indoeuropeo ${ }^{21}$ en que cómpre segmentar Conis-torgis ou Con-is-torgis, e así faise mais problemática a súa relación formal, nunca probada, con Conimbriga, que non ten neses presuntos paralelos ningún apoio para se segmentar e analizar como Conim-briga.

En fin, para a única segmentación que me parece posible, Coni-mbriga, sigo a proposta etimolóxica de Búa (2000: 44 e 95): -m(b)riga < *-MRG-EH ${ }_{2}$, de $I E W 738$ *MEREG- 'Rand, Grenze', con epéntese de - $b$ - na secuencia - $m r$-; véxase o coñecido escolio a Xuvenal, brogae Galli agrum dicunt, cf. irl. mruig, bruig 'país, territorio', lat. margo, got. marka, o noso xermanismo marca, marcar. A relación entre 'límite' e 'territorio' e os seus respectivos rendementos onomásticos non necesitan presentación e para o grao cero que necesitamos, *-mrg- > -m(b)rig-, son ilustrativos o epíteto teonímico lusitano Malu-mrico (Búa 2000: 44) e a variación do étnico galo Allobroges (*-M(B)ROG-) / Allobriges (con reduccción de $m b r$ a $b r$ ). Pero hai que ter en conta que no galo Allobriges e afíns puido haber influxo dos com-

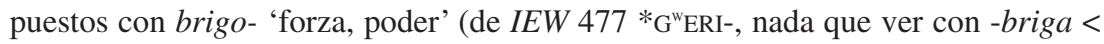
$\left.*_{\mathrm{BHRGH}}\right)^{22}$, ademais de que non se pode desbotar o influxo do tipo Sego-briga (de * ${ }_{\mathrm{BHRGH}}$ ) sobre o tipo de Coni-mbriga e demais formas que aquí revisamos. Deixo de lado qué poida significar o segmento Coni-.

A mesma proposta etimolóxica, un segundo termo - $m(b)$ riga $<*-{ }_{-} \mathrm{MRG}_{0} \mathrm{EH}_{2}$, de $I E W$ 738 *MEREG- 'Rand, Grenze', se pode considerar para os topónimos Calambre (Tapia O), Cambra (Aveiro BL), Cambra, A (Ribeira C, Lugo LU, Mondariz PO), Cambre (Cambre, Carballo e Malpica C), Combre (Lourenzá LU), Enxembre (Salvaterra PO), Oímbra (Oímbra OU), Pambre (Palas LU, Ramirás OU), Sembra (Cee C), Sesimbra (Setúbal E) e Tembra (Brión C) ${ }^{23}$. Non podo facer propostas etimolóxicas seguras para tódolos primeiros termos deste conxunto de topónimos, pero creo que hai un par deles que suxiren e mesmo impoñen unha segmentación con segundo termo -mbra, -mbre que nos arreda do grupo -briga, -brix,-bris, -bre ... (de *-BHRgGH-) e mais tamén da alternativa, xa rexeitada, IEW $1151.2 *$ WER-, erweitert *WER-D-, *WER-S- 'erhöhte Stelle', pero que nos leva a un segundo termo -mbriga $<*$ - $\mathrm{MRG}_{0}-\mathrm{EH}_{2}$.

21 A non indoeuropeidade deste material é a opinión tradicional e maioritaria con apoio bibliográfico enorme, cf. xa Untermann (1961). Que Conistorgis e o seu grupo son do indoeuropeo que entra temperán en Hispania e ten a súa maior densidade onomástica na área meridional é a nova posición de Villar (2000); véxanse en especial cap. 11 e 17.

22 Véxase Schmidt (1957: 155-157).

23 Deixo fóra Vilachambre (Baralla LU), que é un *Villa Flammulae (Moralejo (1977: 74). Cambrelle (Carballo C) parece antroponímico, pero non podo excluír que estea relacionado con Cambre, Cambra. Tamén deixo fóra o portugués Cambres (Lamego BA) porque o xa medieval Cambres apunta, seica, a outra orixe, véxase Fernandes (1999) e tamén deixo fóra Gombra (Vilanova PO), que é xermánico (Piel Kremer 1976: 160). 
O topónimo portugués Cambra, medieval Calambria, Caambria, Caambraha, Caumbria, Kalumbria ${ }^{24}$, é equiparable ó asturiano Calambre (Tapia O), medieval Calambre, e mais ó galego Cambre, medieval Calamber, Calambre, Calambria ${ }^{25}$. No repaso dos repertorios onomásticos hispánicos (e tamén extrahispánicos) é fácil identificar un elemento cala- con - $l$ - simple intervocálico que se perde no ámbito galaico ou se mantén como - $l$ - fóra dese ámbito, mais tamén un call $(a)$ - con fonema líquido xeminado que se conserva como - $l$ - simple no ámbito galaico: o inventario podería ser maior, pero ímolo reducir ó Cale que está na base de Portugal; *Calabri $(g)$ a, deducible de Calabriensis, Galebriensis, e que tamén é medieval

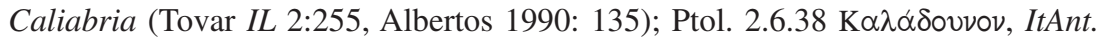
422.5 Caladuno ${ }^{26}$; Calagurris, Calagorra, K $\alpha \lambda \alpha \kappa o p i ́ v \alpha, ~ K \alpha \lambda \alpha \gamma o p i ́ v \alpha$, actual Calahorra, con outras variantes e derivacións (Tovar IL 3 C-330, C-439, C-440; TIR K-30:75); *Calantica (a deducir de dat. sg. Calantice(n)si) (Guerra 1999: 374); hai ademais dúas Calubriga galaicas, a deducir do étnico Calubrigensis (Albertos 1990:135), nas que o - $u$ - poida que sexa secundario, acomodación de $*_{-} a$ - (¿ou $\left.*_{-o}-?\right)$ ó fonema labial seguinte. No capítulo de $*_{-} l l->-l$ - mantido no ámbito galaico, temos, seica, Callaecia / Gallaecia ${ }^{27}$ e o actual Calavre (Santarém $\mathrm{R})$, ademais de que algunhas das formas de documentación soamente antiga e con grafía - $l$ - puidesen ter realmente xeminada - $l l-$; hai ademais antropónimos como Calaetus, Calatus, Calatius ...(cf. Abascal: 103, 310).

Poida que para todos eses nomes estean en xogo orixes e conexións diferentes ou poida que para todos abonde cunha mesma raíz indoeuropea, mais o que agora cómpre salientar é o contraste de *CALA-BRI(G)-, Calia-bria, Calu-briga, Cala-vre (todos eles de *KAL(L)A-BHRG-, é dicir, do conxunto -briga) con Cala-mbria, Cala-mbre, Ca-mbra, Ca-mbre, nos que se impón *KALA-M(B)RुG-, é dicir, outra segmentación e outra etimoloxía no segundo termo.

Se todo o conxunto admite unha orixe única no seu primeiro termo, podemos pensar en IEW 523.1 *KAL- 'hart', *KAL-NO, *KL-NO- 'Schwiele, harte Haut' (cf. os

${ }^{24}$ Cf. Silveira (1914); vexo en Silveira (1914: 121) que a Cambra (Viseu, BA) que recolle Villar (1995a: 158) non encaixa no grupo de *-BRIGA porque a súa documentación medieval Cambar, Camvar, Cambara e os seus inmediatos hidrónimo Cámbar e topónimo Cambarinho apuntan noutras direccións etimolóxicas que tamén poden afectar a Cambres (Viseu, BA), med. Cambares, Cambres. Véxanse posibles paralelos cántabros en García Alonso (1995).

25 A Calambria gala da Tabula Peutingeriana (Holder: I, 688) pode estar neste grupo ou pode ser composto coa base hidronímica *-MBHR- que vimos antes.

${ }^{26}$ Cito esa forma con reservas verbo da súa segmentación e etimoloxización porque os topónimos con segundo termo -dunum son sempre sospeitosos en Hispania, cf. Guerra (1999) s.u. Caladunus. Na autorización desta e demais formas de toda esta restra procuro evitar a palla farragosa, abonda coa citación que fago. En Holder (I, 685-706) hai moito material con cal(l)-, pero non todo da mesma orixe.

27 Véxanse, Moralejo, J. (2000) e (2001). 
calos, cast. callos), de presencia pancéltica abundante e tal vez relacionable con

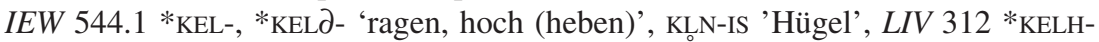
'aufragen, hochragen' (cf. lat. collis, ex-cellere ¿cf. Celtae?), se a aspereza ou dureza no terreo ten conexión coa nota de elevación; ademais de que as dúas raíces anteriores poidan ser totalmente independentes, tampouco non se descarta por algúns autores unha orixe preindoeuropea, *KARA / *KALA 'rocha $>$ abrigo $>$ fortificación'. Ó remate poderiamos ter unha ${ }^{*} \mathrm{CAL}(\mathrm{L}) \mathrm{A}-\mathrm{BRIG}$ - 'vila ou castro forte, da altura, do outeiro' ou 'vila ou castro da rocha' > Caliabria, Calavre ... fronte a unha *CALA-MBRIG- 'marca ou terreo forte, da altura, do outeiro' ou 'marca ou terreo da rocha' > Calambria, Calambre, Cambra, Cambre ...

Temos ademais un Combre, que non sei se terá algunha relación certa co asturiano Colombres e que podería ser un *colombris (ou *calombris) con vocalismo $o$ a contrastar co vocalismo a de Cambre, Calambre, Calavre ... un contraste que na documentación hispánica ten dado pe a discusión verbo de diferenciación de aportes na indoeuropeización. Pero o vocalismo o tamén podería ser secundario, de acomodación do fonema vocálico ó seu contexto consonántico (gutural e labial). Para a súa etimoloxía podemos pensar nas mesmas raíces que para Cambre.

No que portén a Pambre, medieval Paambra e Pambre, é tentador conxecturar perda de $*-l$ - intervocálico no primeiro termo *pala-, que podemos remitir a un conxunto tan atractivo como problemático de étimos e documentación: en primeiro lugar, o IEW 807 *PELI-S, *PEL-S- 'Fels'; ademais os célticos LEIA A-29 ail 'rocher, grosse pierre', A-61 all 'rocher, escarpement' (cf. top. galo Alesia 'La Roche'), e LEIA A-32 aile 'barrière, défense, protection', a comparar coas formas xermánicas asax. faled, dan. fold 'curro': nótese que do punto de partida ide. *p temos o resultado céltico de perda total de $p$ fronte á Lautverschiebung xermánica (lei de Grimm) *p>f, mentres que no noso *pala- e afíns que logo imos ver mantense o* ${ }^{*}$-, cousa que é de longa e viva polémica no diagnóstico da celticidade dunha parte do material hispánico, en especial material lusitano e galaico ${ }^{28}$.

Tamén se mantivo o *p no celta lepóntico palam 'estela funeraria', é dicir, unha especialización do xenérico 'rocha, pedra'; unha especialización semellante pode habela no lat. palatum ou palatus, co derivado palatare productivo nas linguas románicas: o significado de padal ou bóveda da boca poida que arrinque do xenérico de cuberta ou peche (de pedra), é dicir, a mesma liña de evolución semántica que se pode ver nos exemplos célticos e xermánicos nos que as pedras son o material co que se fan as defensas e os curros.

Outro paso adiante neste sarillo de hipóteses é que lat. palatum ou palatus parece ter moito que ver co orónimo Palatium e co seu derivado palatinus: Varrón, que

28 Abonde con remitírmonos a Villar (1995b) e a Untermann (1987). 
fala dos pastores Palatini (LL 5.54), nos di que eundem hunc locum [Palatium] a pecore dictum putant quidam (LL.5.53) ${ }^{29}$. De este lat. palatium, posible 'curro', fai Best (1989: 339) comparanza co búlgaro medieval polati e moderno poljati, o 'apsidal sheppy' xa prehistórico en áreas indoeuropeas; adxuntamos as formas xermánicas xa citadas faled, fold 'curro' e as conclusións a que chegou Best (1989: 340) de que "**PALATIOM may be considered to be the proto-Indo-European technical term to designate the apsidal shepherd's house annex sheppy'.

En Galicia temos aínda vivos os comúns pala e paleira para significar cavidades na rocha que serven como refuxios do gando e dos pastores, e son termos con abundante rendemento (tamén en Portugal) en topónimos, hidrónimos e orónimos Palas, A Pala, A Paleira, A Palela, Pala do Oso, río da Pala, Água da Pala ... e outras formas que coa súa - $l$ - actual esixen *-ll- (o que temos, seica, no medieval Palla Auria relativa a Ourense no Liber Fidei bracarense, ${ }^{\circ}$ 11, ano 569); estas formas pódense derivar da raíz ampliada *PAL-S-A- ${ }^{30}$, mentres que no caso de *PALA-M(B)Rg- > Paambra, Pambre haberá que contar con *PAL-A- para a perda de *-l-. Pambre poderia ser 'marca ou terreo da rocha, do penedo's1.

Paambre, O Pambre é topónimo en Ramirás OU, pero en Antas de Ulla LU Paambra, Pambre é topónimo, orónimo e hidrónimo (afl. Ulla); ademais de que a nosa análise presupón que ambos Pambre teñen que se referir primariamente a entidades de poboación, a revisión dos textos medievais de Sobrado dos Monxes deixa claro que o uso hidronímico actual de Pambre é secundario e aplicable soamente a un treito do río (que é tamén Ferreira e Merlán, polas poboacións polas que pasa). Tanto para $O$ Pambre de Ramirás OU como para Pambre de Antas LU tamén cabería pensar en IEW 798. 1 *PEL- ... 'gießen, fließen ...', é dicir, en *PALA-MBRIGteriamos a 'marca ou territorio do río' (Arnoia e Ulloa, respectivamente). Esta opción ten a pequena eiva de que parece que na Gallaecia non hai outros exemplos de ese ide. *PEL- 'fluír'.

${ }^{29}$ O sentido de 'residencia', 'pazo' é serodio, debido a que no Palatium ou Palatinum estaba a residencia imperial. Ó palatium 'curro' dos pastores engádase que é Pales a dea pastorum e as súas festas Palilia dicebantur segundo Festo.

30 Non se exclúen outras bases, por exemplo *PAL-N-A-.

${ }^{31}$ Na documentación antiga temos Trebopala (¿topónimo? ¿teónimo? ¿outro tipo de nome?) na inscrición lusitana do Cabeço das Fráguas, o epíteto teonímico lusitano dat. sg. Toudopalandaigae, máis dunha vila Pal(l)antia, etc. Poderian encaixar tamén na hipótese de *PAL(A)- como 'rocha, penedo' que pode evolucionar a 'abrigo, refuxio' e 'curro', pero teñen a alternativa da raíz IEW 786 *PĀ- : Pд- ... 'füttern, nähren, weiden, $L I V 787$ * $\mathrm{PEH}_{2}$ 'hüten, weiden', sufixada con *-lo-. Téñase en conta que esta raíz é a que temos no léxico básico latino do gando e do seu coidado, pāsco, pāstor, pābulum, con paralelos noutras linguas indoeuropeas. Nótese que a idea de 'protección' está nas dúas liñas etimolóxicas ('rocha' e 'pastor') e que o significado de 'rocha, penedo', mesmo divinizado, encaixa ben no mundo cultural céltico. 
Non é momento de discutilo, pero habería que lle dar unha axeitada a fondo ós moitísimos Paços, Pazos, Paçós, Pazós, Pacios, Palacios ... da toponimia galega e portuguesa, xunto cos moitos Palacio(s), Palazuelo(s), etc. que abundan noutras áreas da Hispania indoeuropea. Hai Pazos, Pacios e Palacios de máis como para os reducir todos ó latín e ó significado tardío, e tamén frecuente, que temos nos pazos de Oca, Mariñán, Brejoeira, etc.

Para os topónimos galegos Enxembre, Sembra e Tembra en principio pódese descartar que o grupo - $m b r$ - xurda por síncope de vocal átono postónico e conseguinte epéntese de $-b$ - para facilitar a articulación do grupo $-m r$-, por exemplo, *TÉmARA > *TEMRA > Tembra, pero non podería propor un descarte absoluto dese proceso. Nótese que a sufixación átona -ara, -aro é abundante e estable na Onomástica galaica (Guítara, Lóuzara, Azúmara, Tállara, Présaras, Ézaro, Láncara ...) e non falta no léxico común (cómaro, túzaro, pícaro ...), pero Tamaris > Tambre contradí o que digo e puidera ser de aplicación ó inmediato Tembra. Ademais tampouco non se pode excluír que algunha de esas formas teña orixes moi diferentes das que agora nos ocupan.

No que portén ó galego Oímbra, medieval Olimbria ${ }^{32}$, e ó portugués Sesimbra, medieval Sesimbria, limítome a sinalar que os primeiros termos Oli-, Sesi- coinciden con Coni- (de Conimbriga) na súa vocal final - $i$-, que é frecuente na onomástica hispana tradicionalmente considerada non indoeuropea (por exemplo, Sexi, Urci, Erbi $i^{33}$...; para Sesimbra parece haber outras conexións ou semellanzas na onomástica con ses-, sis- (a ceca ibérica s.e.s.a.r.s., Sisapo, Sisipo, Sisoraca, etc. e tamén antropónimos ${ }^{34}$ ) pero este apontamento non é decisión expresa polo carácter híbrido de Oímbra, Olimbria e Sesimbra, Sesimbria, con primeiro termo non indoeuropeo.

E vou rematar coa obviedade de que a coincidencia de contextos fónicos e morfolóxicos entre os compostos con *-BHRGH- > -briga 'altura > castro, vila' (Nemetobriga) e os compostos con *-M(в)RूaH- > -mbriga 'linde, territorio' (Conimbriga) fai que ambos teñan as mesmas variantes, é dicir, temos -briga, -bria, -bra, -brix, -bris, -bre e temos -mbriga, -mbria,-mbra, (*-MBRIX, *-MBRIS), -mbre. Madia leva, non se descartan cruces e influxos entre ambos tipos.

\footnotetext{
32 A forma Olisimpria nun documento do mosteiro de Celanova é o típico floreo notarial suxerido pola ben coñecida Olisip $(p) o(n a)$, actual Lisboa.

33 Exemplos en Villar (2000: cap. xv).

${ }^{34}$ Exemplos en Villar (2000: 342).
} 


\section{Bibliografía}

Abascal, J. M. (1994): Los nombres personales en las inscripciones latinas de Hispania (Murcia: Universidad Complutense de Madrid, Universidad de Murcia, Universidad de Alicante).

Albertos, M. L. (1990): “Los topónimos en -briga en Hispania”, Veleia, 7: 131-146.

Arbois de Jubainville, H. d' (1893 - 1894): "Les Celtes en Espagne”, Revue Celtique, 14: 357-395; 15: 1-61 e 160-173.

Best, J. (1989): “Comparative Indo-European Linguistics and Archaeology”, JIES, 17: 335-340.

Blondin, R. (1977): "Le toponyme Conimbriga", Conimbriga, 16: 145-159.

Búa, C. / Lois, S. (1995): “Los topónimos gallegos en -bre de origen prerromano”, $B N$ NF, 29-30.1: 13-41.

Búa, C. (2000): Estudio lingüístico de la teonimia lusitano-gallega. Tesis doctoral (inédita) (Universidad de Salamanca).

Caro Baroja, J. (1946): Los Pueblos de España: ensayo de Etnología, I (Barcelona: Barna).

Caro Baroja, J. (1947): "La geografía lingüística de la España antigua a la luz de la lectura de las inscripciones monetales", BRAE, 26 (= Sobre la lengua vasca y el vasco-iberismo: 121-169; San Sebastián: Editorial Txertoa, 1979).

Caro Baroja, J. (1954): "La escritura en la España prerromana”, en Menéndez Pidal, Historia de España, I. España prerromana, 3. Etnología de los pueblos de Hispania: 677-812 (Madrid: Espasa - Calpe).

CIL, Corpus Inscriptionum Latinarum.

Encarnação, J. de (1975): Divindades indígenas sob o domínio romano em Portugal. Subsídios para o seu estudo (Lisboa: Imprensa Nacional - Casa da Moeda).

Fernandes, A. de A. (1999): Toponímia portuguesa. Exame a um dicionário (Arouca, Associação para a defesa da cultura arouquense).

Ferreiro, M. (1990): Gramática histórica galega (Santiago: Edicións Laiovento).

Garcia, J.M. (1991): Religiões antigas de Portugal. Aditamentos e observações às 'Religiões da Lusitânia' de J. Leite de Vasconcelos. Fontes Epigráficas (Lisboa, Imprensa Nacional - Casa da Moeda).

García Alonso, J.L. (1995): "La contribución de la toponimia prerromana de la Península Ibérica al conocimiento de las lenguas paleohispánicas. Los nombres de los cántabros”, en Agud, A. / Fernández Delgado, J.A. / Ramos, A., Las lenguas de corpus y sus problemas lingüísticos: 55-67 (Salamanca: Ediciones Clásicas - Universidad de Salamanca). 
Guerra, A. (1999): Povos e lugares pré-romanos do Ocidente peninsular. Disertação de Doutoramento (inédita) (Universidade de Lisboa).

Holder, A. (1896-1907): Alt-celtischer Sprachsatz (Leipzig: Teubner Verlag).

IEW, Pokorny, J. (1994) [1959]: Indogermanisches Etymologisches Wörterbuch, 2 vols. (Tübingen und Basel, Francke Verlag).

Krahe, H. (1954): Sprache und Vorzeit (Heidelberg: Quelle \& Meyer).

Krahe, H. (1955): Die Sprache der Illyrier, I (Wiesbaden: Otto Harrasowitz),

Krahe, H. (1962): “Die Struktur der alteuropäischen Hydronymie”, AAWL, 5: 286-348.

Krahe, H. (1964): Unsere Ältesten Flussnamen. (Wiesbaden: Otto Harrassowitz).

LEIA, Vendryes, J., Lexique étymologique de l'irlandais ancien. Lettre A, 1959. Lettre B, par les soins de E. Bachellery et P.-Y. Lambert, 1980. Lettre C, par les soins de E. Bachellery et P.-Y. Lambert, 1987. Lettres MNOP. Lettres R-S, 1974. Lettres T-U, par les soins de E. Bachellery et P.-Y. Lambert, 1978. (Dublin: Institute for Advanced Studies - Paris: Centre National de la Recherche Scientifique).

LIV, Rix H (1998): Lexikon der indogermanischen Verben. Die Wurzeln und ihre Primärstammbildungen. Unter Leitung von Helmut Rix und der Mitarbeit vieler anderer bearbeite von Martin Kümmel, Thomas Zehnder, Reiner Lippp, Brigitte Schirmer. (Wiesbaden: Ludwig Reichert Verlag).

Menéndez Pidal, R. (1952): Toponimia prerrománica hispana (Madrid: Gredos).

Monteagudo (1986):, “Toponimia Costera Coruñesa. De Estaca de Bares a Malpica”, Actas do Colóquio "Santos Graça” de Etnografía Marítima 4. Póvoa de Varzim 1986: 29-71.

Moralejo, A. (1953): "Sobre los nombres toponímicos gallegos en -obre y sus afines", en Estudios dedicados a Menéndez Pidal III: 135-157 (Madrid: CSIC) (= Moralejo 1977b: 49-83).

Moralejo, A. (1977a): "Topónimos variables con nasal o sin ella: en -edo/a o -endo/a", Verba, 4: 301-309 (= Moralejo 1977b: 341-354).

Moralejo, A. (1977b): Toponimia gallega y leonesa (Santiago: Pico Sacro).

Moralejo, J. (2000): "De griegos en Galicia", en Alganza, M. / Camacho, J.M.: Epieikeia, Homenaje al profesor Jesús Lens Tuero: 327-358 (Granada: Athos-Pérgamos).

Moralejo, J. (2001): “Gallaecia y sus etimologías”, en Domínguez, M. / Moralejo, J. / Puentes, J.M. / Vázquez, E.: Sub luce florentis calami. Homenaje a Manuel C. Díaz y Díaz: 92-115 (Santiago: Universidade de Santiago). 
Piel, J. M. (1951): "Miscelánea de toponímia peninsular”, $R P F$, 4: 197-227.

Piel, J. M. (1962): Sobre a terminação -endo (-indo), -enda na fito-toponímia galego-portuguesa": Actas do IX Congresso Internacional de Linguística Românica. Universidade de Lisboa 1959: 153-163 (Lisboa: Centro de Estudos Filológicos).

Piel, J. M. (1977): "Sobre os topónimos Conimbriga, Condeixa e Alcabideque", Conimbriga, 16: 161-165.

Piel, J. M. / Kremer, D. (1976): Hispano-gotisches Namenbuch (Heidelberg: Carl Winter Universitätsverlag).

Prósper, B. (2002): Lenguas y religiones prerromanas del Occidente de la Península Ibérica (Salamanca: Universidad de Salamanca).

Roldán, J. M. (1975): Itineraria Hispana, Fuentes antiguas para el estudio de las vías romanas de la Península Ibérica (Valladolid: Departamento de Historia Antigua).

Schmidt, K. H. (1957): "Die Komposition in gallischen Personennamen”, ZCP: 26, 33-301.

Schmoll, U. (1959): Die Sprachen der vorkeltischen Indogermanischen Hispaniens und das Keltiberische (Wiesbaden: Otto Harrassowitz).

Silveira, J. (1914): “Toponymia portuguesa (esboços)”, Revista Lusitana, 17: 114-134.

TIR, Tabula Imperi Romani, (Madrid, 1995 - 2002: IGN, CSIC, Ministerio de Cultura).

Tovar, A. IL, Iberische Landeskunde 1-3 (1974, 1976 e 1989), (Baden-Baden, Valentin Koerner).

Tovar, A. (1957): "Ilirios en España”, BN, 8.3: 278-280.

Untermann, J. (1961): Sprachräume und Sprachbewegungen im vorromischen Hispanien (Wiesbaden: Otto Harrassowitz); versión española en APL X, 1963), versión portuguesa en Revista de Guimarâes LXXII, 1962. A versión portuguesa é máis completa.

Untermann, J. (1987): "Lusitanisch, Keltiberisch, Keltisch", en Gorrochategui, J. I Melena, J. L. / Santos, J.: Studia Palaeohispanica. Actas del IV Coloquio de Lenguas y Culturas Paleohispánicas (= Veleia 2-3): 57-76.

Untermann, J. (1999): “Joan Coromines y la onomástica de la Hispania antigua”, en J. Solà: L'obra de Joan Coromines. Cicle d'estudi i homenatge: 183-192 (Sabadell: Fundació Caixa de Sabadell).

Untermann, J. (2001): "La toponimia antigua como fuente de las lenguas hispano-celtas", Palaeohispanica, 1: 187-212. 
Villar, F. (1995a): Estudios de celtibérico y de toponimia prerromana (Salamanca, Universidad de Salamanca).

Villar, F. (1995b): Los indoeuropeos y los orígenes de Europa (Madrid: Editorial Gredos).

Villar, F. (2000): Indoeuropeos y no indoeuropeos en la Hispania prerromana (Salamanca: Universidade de Salamanca). 